\title{
The Use of Mindfulness Practices to Relieve Symptoms of Anxiety and Migraine Headaches
}

\author{
Dorothy Sisk* \\ Department of Human Development, Lamar University, USA
}

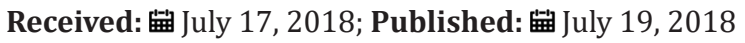

*Corresponding author: Dorothy Sisk, College of Education \& Human Development, Lamar University, USA, Tel: 409-880-8046;

Email: siskda@lamar.edu

\begin{abstract}
Intellectually gifted students have emotional intensity and mental processing that is outside of the norm for their age group and they often manifest anxiety about school and have difficulties in peer interaction. This anxiety often results in migraine headaches and a feeling of being "out of sync" with both school and their peers. Programs focusing on building motivation, self-concept and leadership are one way to meet the social-emotional needs of gifted students. Shayla a 16yr. old gifted student suffered from migraine headaches and she had a low self-concept. After participating in a three weeks residential leadership program focusing on mindfulness practices, she became free from migraine headaches, and there was a significant increase in her self-concept, motivation and leadership skills.
\end{abstract}

\section{Introduction}

Today schools as a result of a current focus on achievement and test results tend to teach toward memory and recall, neglecting the higher levels of thinking that intellectually gifted students need, and the result is that gifted students underachieve, procrastinate in school work they have already mastered [1]. These gifted students may become behavior problems they face endless hours of boredom in the regular classroom. Stephanie Tolan in her book Out of Sync [2] said the capacities of mind that make up giftedness can create what she calls oddity of eminence; the unremarkable or the spectacular. For the individual gifted student these capacities can create fulfillment and success or pain and confusion. Anxiety and an overall apathy for school and social interaction are often a result of a lack of challenge [3]. Mindfulness practices have been used successfully with adults by Jon Kabat -Zinn in the Mindfulness -Based Stress Reduction (MBSR) Clinics. Randomized controlled trials and studies have shown impressive reduction in psychological morbidity associated with medical illness after mindfulness training, as well as a reduction of stress and enhanced emotional well-being in non-clinical samples [4].

Marsha Linehan, a pioneer in Social Emotional Learning (SEL) uses mindfulness strategies to develop five social emotional competencies:
a) self-management,
b) self-awareness,
c) social awareness,
d) relationship skills, and

e) responsible decision-making [1]. Shayla (not the real name) is a 16 years old gifted adolescent suffering from migraine headaches, a low self-concept and difficulty in relating to her peers. In addition, she is not motivated about school work and is seldom involved in any type of leadership activity.

\section{Student Description}

Shayla is in the 11th grade in a public school that provides Advanced Placement classes for high ability and gifted students, but there is little or no counseling available for her social-emotional needs. She is an A/B student, but puts little or no effort in daily work and waits until the last minute to complete assignments with the accompany anxiety resulting from that behavior.

\section{Case History}

Shayla was referred to the gifted program during second grade in her school as a result of her advanced vocabulary and reading level on the Iowa Test of Basic Skills at the sixth grade level. She was administered a WISC and achieved an intelligence quotient of 140. In the elementary school, she was able to explore projects of interest using problem based learning activities, and she was placed in a classroom with a cluster of other gifted students. At the middle school level, there were no provisions for Shayla as a gifted student, and she began to underachieve, to have headaches and wanting to stay home. She was on medication for her migraine headaches and showed little interest in school. As a result, she was not nominated for the Pre-Advanced Placement Classes for able students. In high school, her parents insisted that she be included in at least one AP class, and she was enrolled in the AP Math classes for her 
Freshman, Sophomore and Junior year; however, she did not take the tests for credit, as her teachers and she felt that she could not pass the test. Her mother researched summer programs for high school gifted students and found the Texas Governor's School at Lamar University in Beaumont, Texas, and requested an application for Shayla. Her application was reviewed by a selection committee who recommended that she be accepted and a treatment plan be designed for her.

\section{Treatment Plan}

Shayla was enrolled in the Texas Governor's School in June 1029, 2018 and assigned to a Senior Counselor with 15 other gifted adolescents in what was designated as a "family." The students came from throughout the state of Texas, and reflected the diversity of the state. In the three week residential program, Shayla shared a room with one other young lady. Each counselor was trained to use mindfulness practices with their family members. A major emphasis of the program was focused on a growth mindset. The counselors worked with their family members for 30 minutes each evening and taught them to do the deep breathing exercises of breathing in $1-2-3$, holding the breath for $1-2-3$ and exhaling for $1-2-3$, and the students were told to do this when they were ready for bed. They also experienced body scans and walking meditations. When they did walking meditations, they were asked to focus their attention on their breath, and reminded that the walking meditation would stop their thinking, blaming and judging. This mindfulness practice was based on the teachings of Thich Nhat Hanh [5]. The students also reflected in a daily journal on their experiences in the program, and they were given opportunities to share their entries in the meetings with their counselors. They were guided to become absorbed in the moment, the "here and now" and to practice attention, getting in touch with their senses in activities such as mindfully eating a raisin. The students also were asked to make mental photographs of good moments that they could focus upon at a later time.

\section{Expected Outcome}

It was expected that Shayla would positively interact with the girls in her family and become less anxious as she learned to use the breathing meditation to calm herself. Another expected outcome was a positive increase in her motivation, self-concept and leadership.

\section{Actual Outcome}

Shayla was able to use the deep breathing and meditation to calm herself to the point that her migraine headaches stopped, and she did not need the medication (Nortriptyline). She interacted with not only her family members and counselor, but she was observed interacting with most students in an easy positive and friendly manner. Shayla also took a leadership role in her classes that researched environmental issues, chairing one of the panel discussions. Her positive feelings about the program were reflected in her request for an application to return next summer as a junior counselor. Shayla was administered a Leadership Skills and Behavior Scale as a pre and post- test. Her pre-test in self-concept was 18 and post- test was 20; her motivation pre-test was 27 and posttest was 30 . This change was significant at the .05 level Her overall leadership pre-test was 146 and post-test was 157.

\section{Discussion}

This case is noteworthy in that it addressed an important problem of intellectually gifted students, that of anxiety and the consequential migraine headaches that can negatively affect their achievement and social- emotional well- being. Mindfulness is particularly effective for gifted students, for as the mindfulness practices are learned and internalized, there is improvement in their overall well-being. Gifted students are out of sync with other students, and they feel this at an early age unless they are provided opportunities to learn with other gifted students. Shayla reiterated what so many gifted students say, "I thought something was wrong with me." As gifted students learn more about what it means to be gifted, they become more comfortable with themselves and able to positively interact with others.

\section{Conclusion}

The key points in this case study are the positive effects of the use of mindfulness practices with intellectually gifted students and opportunity to learn with other intellectually gifted students. It is essential that parents and teachers understand the social-emotional needs of gifted students, and the importance of mindfulness practices such as focusing on the here and now, deep breathing and meditation which can transform a classroom and home. In our troubled times, mindfulness offers a strategy for transformation and change. Just the simple act of concentrating on your breath when you are stressed, breathing in 1-2-3 and breathing out 1-23 can calm you and give you time to reflect on the situation. In addition, it is a great way to go to sleep after a challenging day.

\section{References}

1. Sisk D, Kane M (2018) Planting Seeds of Mindfulness. Unionville, NY: Royal Fireworks Press, USA.

2. Tolan S (2016) Out of Sync. Unionville, NY: Royal Fireworks Press.

3. Reis S, Morales-Taylor M (2010) From high potential to gifted performance: Encouraging academically talented urban students. Gifted Child Today 4: 28-38.

4. Wiliams K, Kolar M, Roger B, Pearson J (2001) Evaluation of a wellnessbased mindfulness stress reduction intervention: A controlled trial. American Journal of Health Promotion 115 (6): 422-432.

5. Hahn TN (2015) How to walk. Berkeley, CA: Parallax Press, USA. 


\section{ISSN: 2574-1241}

DOI: $10.26717 / B J S T R .2018 .07 .001445$

Dorothy Sisk. Biomed J Sci \& Tech Res

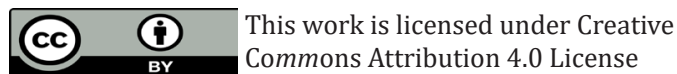

Submission Link: https://biomedres.us/submit-manuscript.php

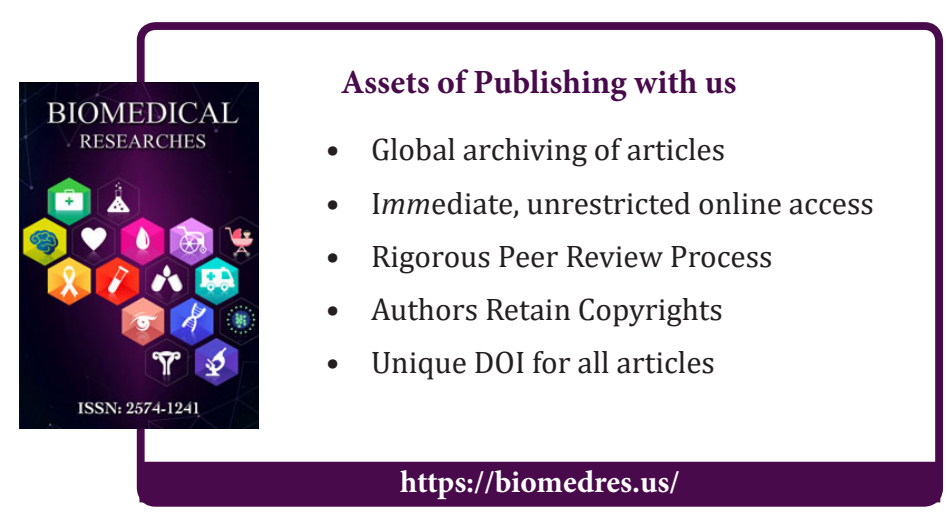

